\title{
A tool to model 3D coarse- root development with annual resolution
}

\section{Journal Article}

Author(s):

Wagner, Bettina; Santini, Silvia; Gärtner, Holger; Ingensand, Hilmar

Publication date:

2011-09

Permanent link:

https://doi.org/10.3929/ethz-b-000040817

Rights / license:

In Copyright - Non-Commercial Use Permitted

Originally published in:

Plant and Soil 346(1-2), https://doi.org/10.1007/s11104-011-0797-8 


\title{
A tool to model 3D coarse-root development with annual resolution
}

\author{
Bettina Wagner • Silvia Santini • \\ Hilmar Ingensand • Holger Gärtner
}

Received: 17 November 2010/Accepted: 12 April 2011/Published online: 3 May 2011

(C) Springer Science+Business Media B.V. 2011

\begin{abstract}
Dynamic root-development models are indispensable for biomechanical and biomass allocation studies, and also play an important role in understanding slope stability. There are few rootdevelopment models in the literature, and there is a specific lack of dynamic models. Therefore, the aim of this study is to develop a 3D growth-development model for coarse roots, which is species independent, as long as annual rings are formed. In order to implement this model, the objectives are (I) to interpolate annual growth layers, and (II) to evaluate the interpolations and annual volume computations. The model developed is a combination of 3D laser scans and 2D tree-ring data. A FARO laser ScanArm is used to acquire the coarse-root structure. A MATLAB program then integrates the ringwidth measurements into the $3 \mathrm{D}$ model. A weighted interpolation algorithm is used to compute cross sections at any point within the model to obtain growth
\end{abstract}

Responsible Editor: Alexia Stokes.

B. Wagner $(\bowtie) \cdot H$. Gärtner

Swiss Federal Research Institute WSL,

Zürcherstrasse 111,

8903 Birmensdorf, Switzerland

e-mail: bettina.wagner@wsl.ch

B. Wagner $\cdot H$. Ingensand

Institute of Geodesy and Photogrammetry, ETH Zurich, 8093 Zurich, Switzerland

S. Santini

Institute for Pervasive Computing, ETH Zurich,

8092 Zurich, Switzerland layers. The algorithm considers both the root structure and the ring-width data. The model reconstructed ring profiles with a mean absolute error for mean ring chronologies of $<9 \%$ and for single radii of $<20 \%$. The interpolation accuracy was dependent on the number of input sections and root curvature. Total volume computations deviated by $3.5-6.6 \%$ from the reference model. A new robust root-modelling tool was developed which allows for annual volume computations and sophisticated root-development analyses.

Keywords Allocation - Laser scanning - Root growth Tree rings $\cdot$ Volume

$\begin{array}{ll}\text { Abbreviations } \\ \text { MAE } & \text { Mean absolute error } \\ \text { MAPE } & \text { Mean absolute percentage error } \\ \text { MC } & \text { Mean ring chronologies } \\ \text { 3D } & \text { 3-dimensional } \\ \text { 2D } & \text { 2-dimensional }\end{array}$

\section{Introduction}

Roots play a key role in the global carbon budget and may influence forests responses to a changing environment (Rasse et al. 2001; Tobin et al. 2007). Root anchorage is also an essential factor in slope stability and there is evidence that biomass allocation to roots is especially important in this process (Reubens et al. 
2007). However, many processes connected to root development and carbon allocation to roots are not well understood (Heimann and Reichstein 2008). To improve understanding of these growth processes, we need to increase the detail of our analyzes, e.g., by modeling these growth processes for a better understanding of forest ecosystems (Lecompte et al. 2001; Tobin et al. 2007). Roots have to be included in these growth models (Brunner and Godbold 2007), because each part of a tree (e. g. shoots, roots, branches) is tightly connected to and dependent on every other components. Thus, no tree operates independently from its roots (Tobin et al. 2007).

Detailed information about the $3 \mathrm{D}$ architecture of root systems is required to completely understand coarse-root structure and functioning (Dupuy et al. 2007, Henderson et al. 1983). In this regard, modelling of root systems is an important step towards the full understanding of root-system development.

Root volume, length and diameter of compartments are the specific measures needed for a more complete quantitative description of root-system architecture and coarse-root distribution (Reubens et al. 2007).

For a long time there was especially a lack of root development studies describing the growth of entire root systems (Tobin et al. 2007). A dynamic view of root architecture is also required to understand tree anchorage, since branching and spreading patterns have to be assessed.

Existing dynamic models for root architecture facilitate analyses of the retrospective and are the link between static observations and dynamic simulations of the root architecture (Pagès and Aries 1988; Lecompte et al. 2001; Vercambre et al. 2003), as calibration of the dynamic models is needed (Lecompte et al. 2001). However, it is not clear if those simulations are able to reconstruct plant development in a realistic way. Simulations predict rather than reconstruct how a root system develops over time (Pradal et al. 2009). Thus, they are assuming that quantitative and qualitative processes are stable in time (Vercambre et al. 2003). The latter is under discussion and hence, there is a need for reliable models, which are truly reconstructing root development. The full potential of reconstructing root development has not been tapped so far.

Because trees are slow growing organisms, long term observations of root-development and the respec- tive data acquisition would be time consuming and therefore, unrealistic for most research studies. For the juvenile phase of trees it is possible to use growth chambers and field rhizotrones to actually observe the root development over time (Le Roux and Pagès 1994; Jourdan and Rey 1997, Pagès and Bengough 1997, Pagès et al. 2004). In contrast, observations of tree-root architecture over time-spans of decades are simply not possible. As well, these practical observations are mostly discontinuous only a part of the entire system is observed (Vercambre et al. 2003) and they might not be representative for actual root development in soils and for root architectural analyses (Lecompte et al. 2001). Another drawback of these studies is that it is not possible to quantify the effective volume development over time.

Although estimations of volume or biomass are possible without 3D models e.g. via fractal analyses (Van Noordwijk et al. 1994), allometric statistical models (Tobin et al. 2007), or equations based on breast-height diameters (Drexhage and Gruber 1999) there is evidence that estimations are not very accurate (Zianis et al. 2005). Estimates are also often species or stand specific because the development of biomass is strongly dependent on site conditions (Tobin et al. 2007) which limit their broader applicability. Another restriction of these models is that they provide only limited information about dynamical growth processes (Van Noordwijk et al. 1994).

It is becoming increasingly important to develop models, which are able to concurrently fulfill different tasks (Tobin et al. 2007). 3D root-development models, which are reliably able to reconstruct coarse root growth, can be an important tool for analyses of root growth (e.g. radial growth, elongation, branching) and volume development over time.

Root-dynamic studies at a long-term scale have only been realized in two ways (Danjon and Reubens 2008), either using chronosequences or using dendroecological studies: (i) Chronosequences are frequently used to analyze different age stages (Jourdan and Rey 1997; King et al. 2007; Genet et al. 2009) and to get information about root development over time. However, even if the site factors are comparable it is still not possible to analyze the reaction of individual trees on specific environmental conditions or events. (ii) Dendro-ecological studies are used for retrospective measurements, which allow for complete analyses of the past growth of trees. For root-growth analyses 
even the positions of the ring-width measurements can be tagged within a 3D model (Danjon and Reubens 2008). This connects the ring-width data to their spatial context. In addition, it is possible to integrate the ring-width data into a 3D structural surface model of a root system (Wagner et al. 2010; Wagner et al. 2011). Entire ring-profiles were directly integrated at different cross sections into a 3D surface model acquired with laser scanning. These models enable more comprehensive analyses of growth processes and the statistical evaluation of growth processes in a spatio-temporal context. However, a full $3 \mathrm{D}$ reconstruction on the basis of the ring-width data has not yet been realized.

Therefore, the scope of the current study is to develop a 3D growth-development model for coarse roots, which is independent of tree species, as long as annual rings are formed. In order to implement this, the objectives are (I) to interpolate $3 \mathrm{D}$ growth layers for every single growth year and (II), to evaluate the interpolations and annual volume computations. The high resolution model is based on two different data sets laser scans and ring-width data. The fusion of these data sets will allow for a 3D spatio-temporal reconstruction of root development on an annual basis. This study is based on the successful integration of tree-ring profiles at defined cross sections into a 3D surface model (Wagner et al. 2011). The model is limited to a certain complexity degree of root systems and should primarily be used for younger trees and those with protruding root systems.

\section{Methods}

A 12 year old pine root system (Pinus silvestris) was excavated in November 2009 within the nature reserve "Loonse en Drunese Duinen" in the Netherlands. The pine grew in sandy soil in an inland dune system. The tree was about $2.5 \mathrm{~m}$ high and the stem at the collar about $8 \mathrm{~cm}$ in diameter. The top soil layers near the tree base were removed by hand and the course of roots followed and gently exposed with shuffles and pickaxes. The entire exposed root system was transported to a storage building where the root system was rearranged and fixed for scanning. Roots with a diameter smaller than $0.5 \mathrm{~mm}$ were removed from the system prior to scanning. In order to acquire the outer shape of the roots a FARO Laser ScanArm (http://www.faro.com/) where the operator directs the scan device interactively along the surface of the root system, was used. The scanner has a resolution of $\pm 50 \mu \mathrm{m}$ (FARO Inc. 2010) and acquires 19,200 points per second.

The resulting raw data are point clouds in the 3D Euclidean space, which require further processing due to noise (e.g. scattering effects) regularly occurring during scanning (Lichti et al. 2005). These artifacts were removed using filter techniques in Geomagic (e.g. outlier detection, uniform sample; http://www.geomagic.com/). The point clouds were then triangulated in Geomagic, which allows for volume computations to the date of uprooting. Based on the scanning and the post processing of the scans, a high resolved 3D surface model was developed representing the outer shape of the root system in a realistic way (Fig. 1a). Volume computations based on the scanner model showed an overestimation of up to $7 \%$ as was tested with water replacement tests (Wagner et al. 2010), referred to as "offset" in the current study. Before scanning the root system the positions for tree-ring measurements were marked with pins (Bert and Danjon 2006). After the 3D structure of the root was accessed, the root was cut into segments at the pinned positions. In most cases, a cut was set every $10 \mathrm{~cm}$. In cases where the root structure was highly curved additional cross sections were cut to guarantee a straightforward interpolation. In general, the discs were cut perpendicular to the axis of growth of the root. The cross sections were sanded and tree-rings measured according to standard techniques in dendrochronology (Cook and Kairiukstis 1990). On each cross section ring-width measurements were done along four radii using the WinDENDRO image-analyzing software (Regent Instrument Inc. 2004). In general, the radii were positioned perpendicular to each other. Nevertheless, sometimes it was necessary to modify the angle due to deformations or cracks. For highly deformed cross sections additional input radii were required. Before the ring-width data could be used, it was necessary to perform crossdating and, to mark the presence of missing rings. For our tree this was very difficult because the tree was only 12 years old, not providing enough rings for proper crossdating. Nevertheless, crossdating is essential for correct dating. If missing rings were detected the coordinates of the previous ring boundary were used twice to mark the occurrence of a missing ring. Therefore, the system 
a

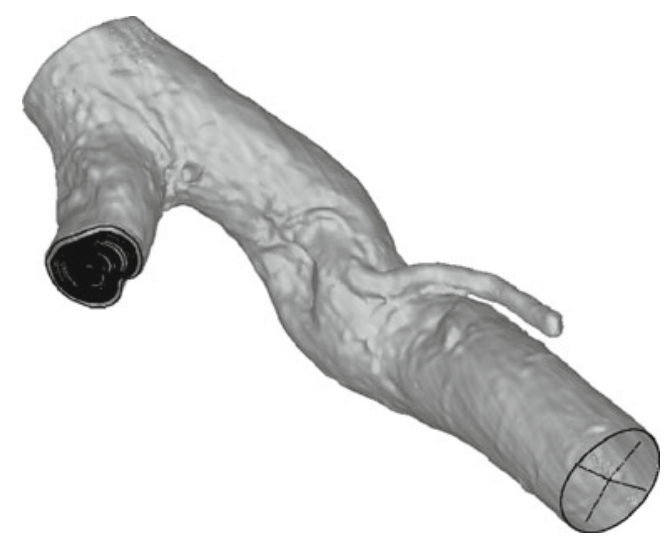

b

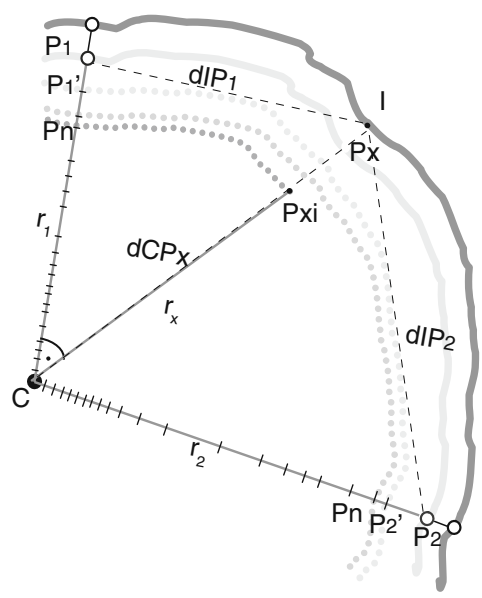

Signatures :

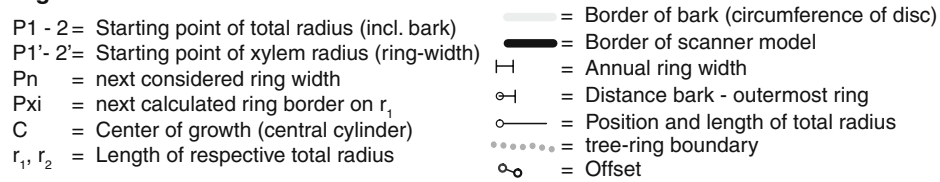

Fig. 1 a Triangulated surface model, acquired with the Laser ScanArm and state of the model after integrating tree-ring radii (right) and entire tree-ring profiles (left) based on ring-width

registers the respective calendar year even though there is no ring. This procedure is required for the correct dating of the plant parts and the proper reconstruction of the growth layers.

WinDENDRO enables ring-width measurements based on scanned images generated by a distortionfree flatbed scanner. Data are provided as text files giving the ring width in $\mathrm{mm}$. As previously presented in Wagner et al. (2011) cross sectional ring-width profiles were incorporated into the 3D surface model (Fig. 1a). On the basis of the integrated ring profiles and the outer structure of the root, a weighted interpolation algorithm was used to reconstruct the data gaps between the adjacent input cross sections. For test purposes, two single roots out of the scanned root system were chosen to apply the model, but ringwidth data is available for the entire system. Root 1 was about $1.6 \mathrm{~cm}$ and root 2 about $1.8 \mathrm{~cm}$ in diameter.

The $3 \mathrm{D}$ reconstruction procedure required five main steps: (I) Point matching between adjacent input cross sections; (II) Insertion of intermediate cross sections; (III) Identification of the coordinates of the growth center of intermediate cross sections; (IV) measurements b Schematic illustration of the 2D interpolation of tree-ring profiles between measured tree-ring radii

Computation of ring profiles of intermediate cross sections; and, finally (V) Computation of annually resolved volume.

(I) First of all, a correspondence between two adjacent input cross sections $\left(\mathrm{CS}_{1}, \mathrm{CS}_{2}\right.$; Fig. 2) was required for the $3 \mathrm{D}$ interpolation, because the individual cross sections had their own reference system. Also the intersection between the cross sections and the 3D model was required. A set of reference points serving as "anchors" for the interpolation function must thus be computed coherently for all cross sections. The first 3D data processing step recomputed the ring-width radii from the profiles of the available input cross sections along polar grids, as schematically depicted in Fig. 3. A polar grid was defined for the first cross section $\left(\mathrm{CS}_{1}\right)$ and was later projected onto $\mathrm{CS}_{2}$. The projection of the polar grid from one cross section to the other worked as follows. The ring-width data of the first cross section, $\mathrm{CS}_{1}$, were computed in $1^{\circ}$ steps resulting in 360 radii, i.e. in the context of this study $n_{\text {total }}$ has been set to 
Fig. 2 Plane used as a reference between two adjacent input cross sections (step I of the interpolation procedure)

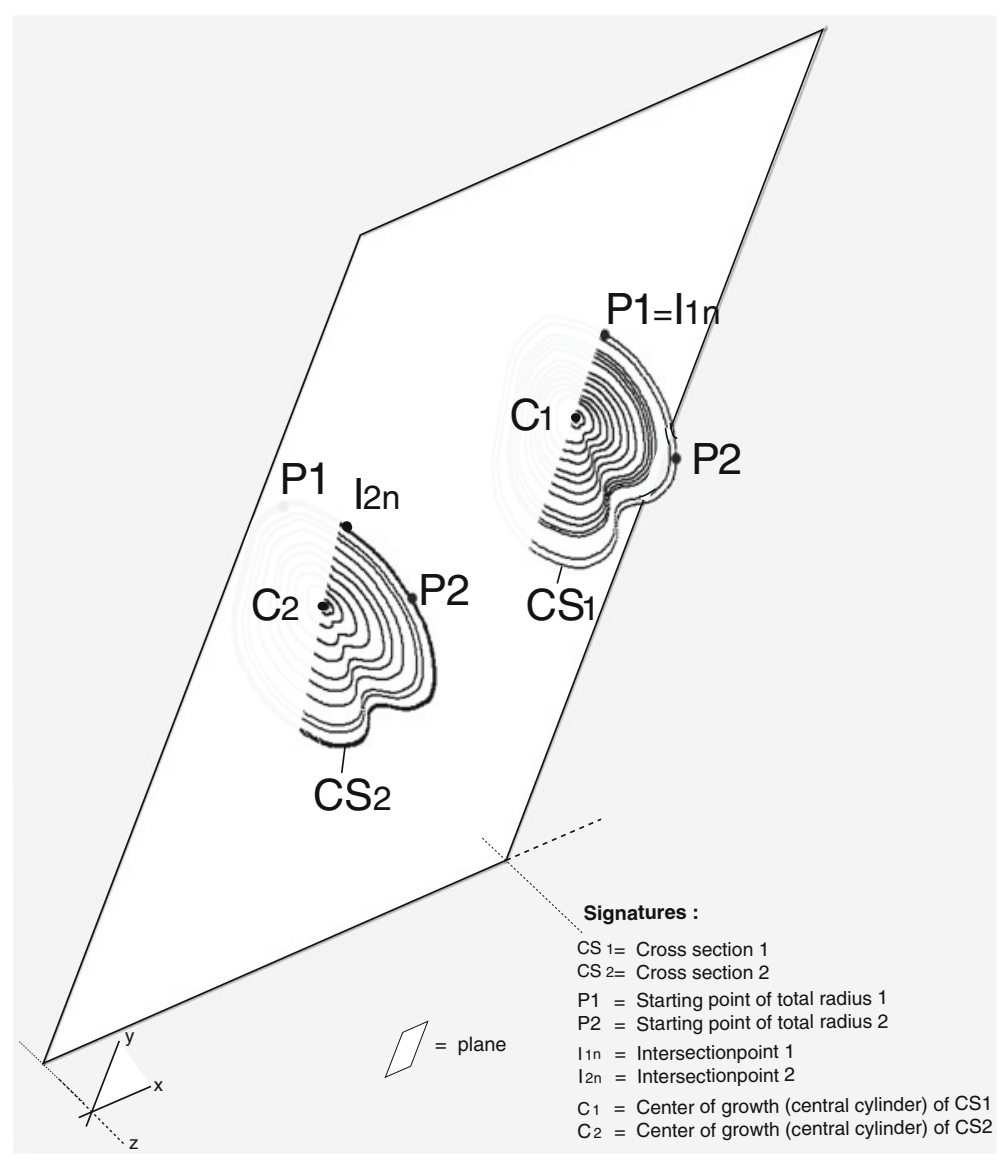

360. As a result, $\mathrm{n}$ is an index standing for $n=1, .$. , $\mathrm{n}_{\text {total. }}$. The $\mathrm{n}$-th radius $\left(\mathrm{r}_{\mathrm{n}}\right.$ of $\left.\mathrm{CS}_{1}\right)$ is a line segment limited by the center of growth $\mathrm{C}_{1}$ and the point $I_{1 n}$, which represents the intersection point of $r_{n}$ with the circumference of the cross section $\mathrm{CS}_{1}$. The set of all $n_{\text {total }}$ radii of $\mathrm{CS}_{1}$ represents the polar grid to project on $\mathrm{CS}_{2}$. This required finding, for each of the $n_{\text {total }}$ radii, the point $I_{2 n}$ on $\mathrm{CS}_{2}$ that was properly aligned with $\mathrm{I}_{1 \mathrm{n}}$. To this end, the plane passing through the three points $\mathrm{C}_{1}, \mathrm{C}_{2}$, and $I_{1 n}$ was computed (Fig. 2), and the point $I_{2 n}$ was determined as the intersection between this plane and the circumference of $\mathrm{CS}_{2}$. Afterwards the plane was rotated in the $1^{\circ}$ steps calculating at each step the respective intersection points and the ring-width radii of $\mathrm{CS}_{2}$ were recomputed on this new grid, using the method described in Wagner et al. (2011). The same procedure was repeated for each pair of adjacent cross sections $\left(\mathrm{CS}_{2}\right.$ and $\mathrm{CS}_{3}$, $\mathrm{CS}_{3}$ and $\mathrm{CS}_{4}$, etc.).
(II) In a next step additional cross sections were calculated between any two adjacent input cross sections (Fig. 3a). With the default settings, 4 additional cross sections were inserted at regularly spaced intervals between each pair of adjacent input cross sections. The number of additional cross sections and also their spacing can be increased or decreased arbitrarily. The additional cross sections can therefore be inserted at any point between the two input cross sections. The method is described exemplarily for one new cross section $\left(\mathrm{CS}_{\mathrm{x}}\right)$ laying between two adjacent input cross sections $\mathrm{CS}_{1}$ and $\mathrm{CS}_{2}$. The index $\mathrm{x}$ refers to any new cross section calculated. In order to retrieve the circumference of the new cross section, a plane was inserted at the desired position of the 3D model (Fig. 3a). The circumference of the new cross section was determined as the intersection between the $3 \mathrm{D}$ root model and the plane having distance $\mathrm{d}_{1}$ from $\mathrm{CS}_{1}$ and 
Fig. 3 Schematic illustration of the interpolation steps (steps II-IV); a Calculating $\mathrm{CS}_{\mathrm{X}}$ from the scanner model (step II); b Defining $\mathrm{C}_{\mathrm{X}}$ of $\mathrm{CS}_{\mathrm{X}}$ (step III); $\mathbf{c}$ interpolation of ring profiles at $\mathrm{CS}_{\mathrm{X}}$ (step IV) a

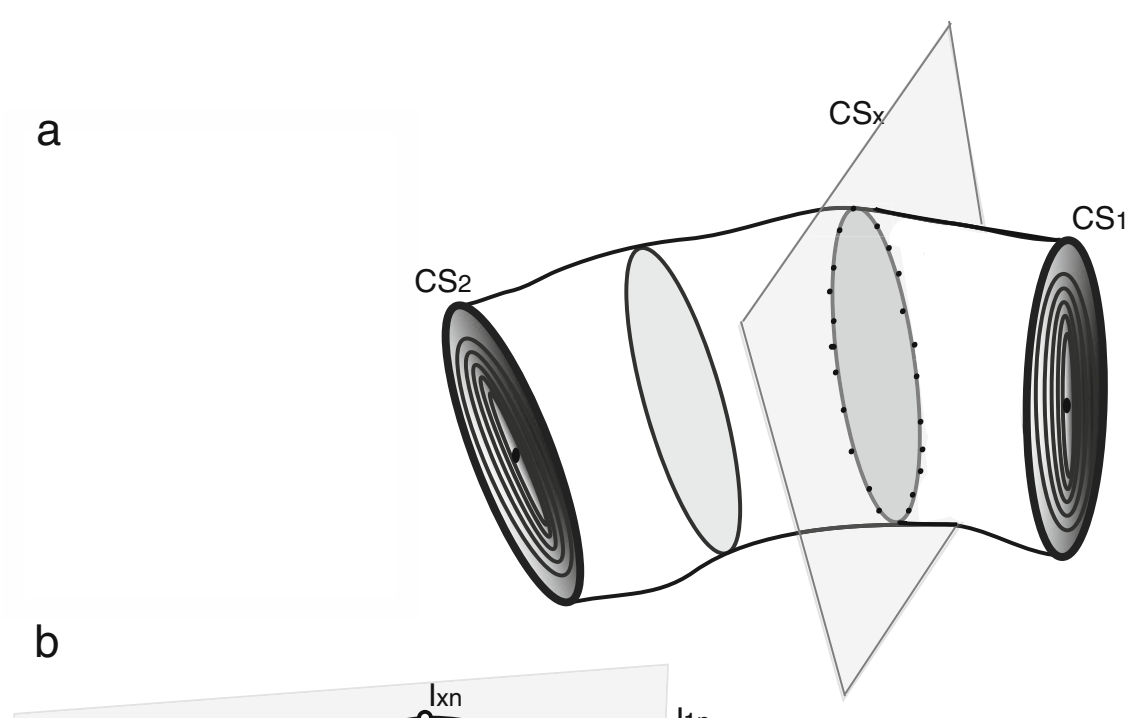

b

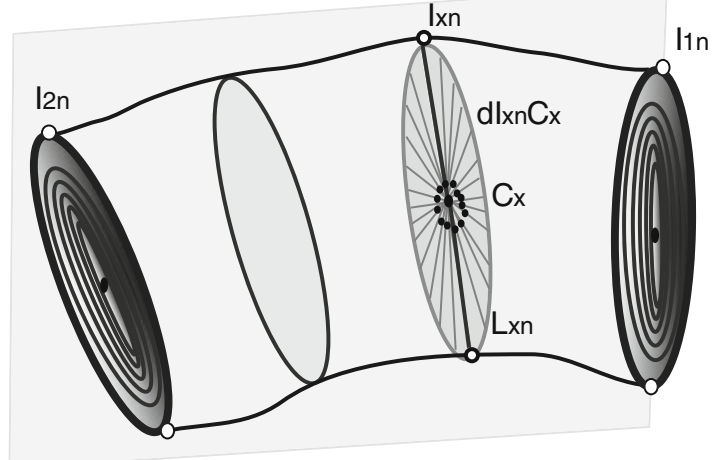

C

\section{Signatures :}

0 = next ring border

0 = offset border

0 = Intersection points

- = Center of growth

= Intersection line Lxn

= Distance dlxnCx

0 Offset

0 = Distance dPxn(i-1)Pxn

$$
=\text { Plane }
$$

$\mathrm{d}_{2}$ from $\mathrm{CS}_{2}$. The input cross sections were usually not truly parallel. Therefore, the orientation of the plane was set to be a weighted average between the orientation of $\mathrm{CS}_{1}$ and that of $\mathrm{CS}_{2}$. Because the $3 \mathrm{D}$ model was available as a point cloud, the intersection between the plane and the point cloud was approximated as follows. The points of the cloud positioned within a certain Euclidean distance to the plane and thus, smaller than a

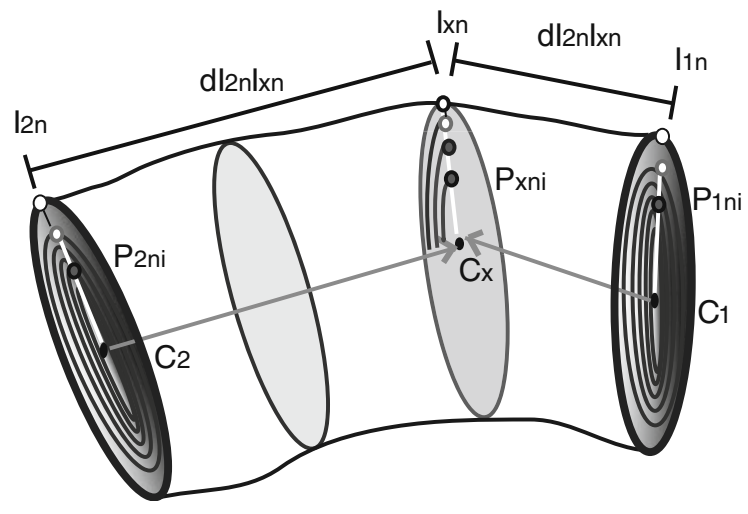

given threshold (default value $d_{T}=0.1 \mathrm{~mm}$ ) were orthogonally projected on the plane. The set of these projected points represented the desired approximation of the circumference of the new cross section.

(III) In the third processing step, the position of the growth center $\left(\mathrm{C}_{\mathrm{x}}\right)$ of each additional cross section $\left(\mathrm{CS}_{\mathrm{x}}\right)$ was computed (Fig. 3b) as a correspondence for the later integration of the ring data. Therefore, $\mathrm{dC}_{\mathrm{x}} \mathrm{I}_{\mathrm{xn}}$ was the unknown 
distance required (Fig. 3b). Although the distances can be estimated, the problem remained to find their correct position within the cross section. Thus, a correspondence within the $\mathrm{CS}_{\mathrm{x}}$ was needed to project the respective distances on the cross section. For that purpose the intersection points $\mathrm{I}_{\mathrm{xn}}, n=1, . ., \mathrm{n}_{\text {total }}$, were first determined using the procedure described in step (I). Applying this procedure also allowed computing an estimate of the orientation of the radii on $\mathrm{CS}_{\mathrm{x}}$ or, in other words, of the lines on which the line segments $C_{x} I_{x n}$ were lying. These lines $\left(\mathrm{L}_{\mathrm{xn}}\right)$ represent the axes of the polar grid of $\mathrm{CS}_{\mathrm{x}}$. The next step in the estimation procedure of the coordinates of the point $\mathrm{C}_{\mathrm{x}}$ determined the unknown distances $\mathrm{dC}_{\mathrm{x}} \mathrm{I}_{\mathrm{xn}}$ between the center of growth $\mathrm{C}_{\mathrm{x}}$ and the intersection point $\mathrm{I}_{\mathrm{xn}}$ for all the radii. These estimates were indicated as $\mathrm{d}^{*} \mathrm{C}_{\mathrm{x}} \mathrm{I}_{\mathrm{xn}}$ and computed as follows:

$$
\mathrm{d}^{*} \mathrm{C}_{\mathrm{x}} \mathrm{I}_{\mathrm{xn}}=\mathrm{dC}_{1} \mathrm{I}_{1 \mathrm{n}} \cdot\left(1-w_{1 n}\right)+w_{1 n} \cdot \mathrm{dC}_{2} \mathrm{I}_{2 \mathrm{n}}
$$

For the estimation of $d^{*} C_{x} I_{x n}$ the following distance was required:

$\mathrm{dI}_{\mathrm{xn}} \mathrm{I}_{1 \mathrm{n}} ; \mathrm{dI}_{\mathrm{xn}} \mathrm{I}_{2 \mathrm{n}} \quad$ Distance between the intersection point $\mathrm{I}_{\mathrm{xn}}$ and $\mathrm{I}_{1 \mathrm{n}}\left(\mathrm{I}_{2 \mathrm{n}}\right)$, which gives a measure of the distance of $\mathrm{CS}_{\mathrm{x}}$ to $\mathrm{CS}_{1}\left(\mathrm{CS}_{2}\right)$

$\mathrm{dC}_{1} \mathrm{I}_{1 \mathrm{n}} ; \mathrm{dC}_{2} \mathrm{I}_{2 \mathrm{n}} \quad$ Distance between the intersection point $\mathrm{I}_{1 \mathrm{n}}\left(\mathrm{I}_{2 \mathrm{n}}\right)$ and the growth center $\mathrm{C}_{1}\left(\mathrm{C}_{2}\right)$, which gives a measure of the respective radii $\left(\mathrm{r}_{\mathrm{n}}\right)$ at $\mathrm{CS}_{1}\left(\mathrm{CS}_{2}\right)$

The defined weight $\mathrm{w}_{1 \mathrm{n}}$ takes into account the relative distance of $\mathrm{CS}_{\mathrm{x}}$ to $\mathrm{CS}_{1}$ and $\mathrm{CS}_{2}$ :

$w_{1 n}=\frac{\mathrm{dI}_{\mathrm{xn}} \mathrm{I}_{1 \mathrm{n}}}{\left(\mathrm{dI}_{\mathrm{xn}} \mathrm{I}_{1 \mathrm{n}}+\mathrm{dI}_{\mathrm{xn}} \mathrm{I}_{2 \mathrm{n}}\right)}$

The $\mathrm{x}-, \mathrm{y}-$, and $\mathrm{z}$-coordinate of $\mathrm{C}_{\mathrm{x}}$ were then computed as follows. For each of the $n_{\text {total }}$ radii, the coordinates of the point $\mathrm{C}_{\mathrm{xn}}$ lying on the line $\mathrm{L}_{\mathrm{xn}}$ and having distance $d^{*} C_{x} I_{x n}$ from $I_{x n}$ were determined. These points represented each an approximation of the growth center. Thus, the $\mathrm{x}-, \mathrm{y}-$, and $\mathrm{z}$-coordinate of the unknown point $C_{x}$ were computed as the average of the $\mathrm{x}-, \mathrm{y}-$, and $\mathrm{z}$-coordinate of all the $\mathrm{n}_{\text {total }}$ estimates $\mathrm{C}_{\mathrm{xn}}$. This approach relies on the assumption that the lines $\mathrm{L}_{\mathrm{xn}}$ approximate with the real radii of $\mathrm{CS}_{\mathrm{x}}$ (Fig. 3b).

(IV) During the fourth processing phase, the ring profiles of each additional cross section $\mathrm{CS}_{\mathrm{x}}$ were reconstructed. For the integration of the new ring profiles a weighted interpolation algorithm was used. Dependent on the distance of $\mathrm{CS}_{\mathrm{x}}$ to $\mathrm{CS}_{1}$ and $\mathrm{CS}_{2}$ a stronger weight was either put on the ring width of $\mathrm{CS}_{1}$ or $\mathrm{CS}_{2}$ respectively. The ring profiles of $\mathrm{CS}_{\mathrm{x}}$ were reconstructed from the two profiles of the input cross sections $\left(\mathrm{CS}_{1}\right.$ and $\left.\mathrm{CS}_{2}\right)$.

As mentioned above the model based on the scan data overestimated the total volume by up to $7 \%$. This resulted for the ring integration in a gap between the outermost point of the radii representing the bark and the circumference of the cross section retrieved by the scanner (Wagner et al. 2010). This offset had no impact on the accuracy of the tree-ring data, as ringwidth values were consistent with WinDENDRO measurements (Figs. 2 and 3c). However, this offset had to be considered for the calculation of the ring profiles.

The offset was calculated separately for $\mathrm{CS}_{1}$ and $\mathrm{CS}_{2}$ :

$$
\begin{aligned}
& \text { offset }_{1 \mathrm{n}}=d C_{1} I_{1 \mathrm{n}}-\sum r w_{1 n} \\
& \text { offset }_{2 \mathrm{n}}=d C_{2} I_{2 n}-\sum r w_{2 n}
\end{aligned}
$$

Then, the corresponding offset for the $n$-th radius of the cross section $\mathrm{CS}_{\mathrm{x}}$ was determined:

offset $_{\mathrm{xn}}=\left(1-w_{1 \text { avg }}\right) *$ offset $_{1 \mathrm{n}}+w_{1 \text { avg }} *$ offset $_{2 \mathrm{n}}$

$\sum \mathrm{rw}_{1 \mathrm{n}} ; \sum \mathrm{rw}_{2 \mathrm{n}} \quad$ the sum of the ring-width data for the individual growth years on $r_{n}$ of CS1 (CS2)

$\mathrm{w}_{\text {lavg }}$ the average of the $\mathrm{n}_{\text {total }}$ weights $\mathrm{w}_{1 \mathrm{n}}$ computed during the third processing phase.

Tree ring interpolations are shown for any new ring border $\left(\mathrm{P}_{\mathrm{xni}}\right)$ laying on $\mathrm{r}_{\mathrm{n}}$ of CS1 (CS2). Each ring 
boundary was identified by an index i. In particular, the index $i=1$ indicated the innermost ring while $i=$ $\mathrm{r}_{\text {total }}$ was the outermost one. The ring of index 0 was a "degenerated" ring that coincided with the center of growth. The point $\mathrm{P}_{1 \text { ni }}\left(\mathrm{P}_{2 n i}\right)$ indicated the $\mathrm{i}$-th ring boundary on $r_{n}$ for $\mathrm{CS}_{1}\left(\mathrm{CS}_{2}\right)$ (Figs. 1 and $3 \mathrm{c}$ ).

For the computation of the ring boundary an additional distance was considered (Fig. 3c):

$\mathrm{dP}_{1 \mathrm{n}(\mathrm{i}-1)} \mathrm{P}_{1 \text { ni }} ; \quad$ Distances between the (i-1)-th and i-th $\mathrm{dP}_{2 \mathrm{n}(\mathrm{i}-1)} \mathrm{P}_{2 \mathrm{ni}} \quad$ ring boundary (i.e., the $\mathrm{i}$-th ring width) on $r_{n}$ for CS1 (CS2).

Using these distances and also the above computed values for $\mathrm{dC}_{\mathrm{x}} \mathrm{I}_{\mathrm{xn}}$ and the offset ${ }_{\mathrm{xn}}$, the following ratios were computed for $i$ that varies between 1 and $r_{\text {total }}$.

ratio $_{1 n i}=\frac{d P_{1 n(i-1)} P_{1 n i}}{d C_{1} I_{1 n}-o f f s t_{1 n}}$

ratio $_{2 n i}=\frac{d P_{2 n(i-1)} P_{2 n i}}{d C_{2} I_{2 n}-o f f \text { set }_{2 n}}$.

ratio $_{X n i}=\frac{d P_{X n(i-1)} P_{X n i}}{d C_{X} I_{X n}-o f f s e t_{X n}}$,

In order to calculate the ring boundaries the offset was subtracted from the overall distance $\mathrm{dC}_{\mathrm{x}} \mathrm{I}_{\mathrm{xn}}$ (Fig. 3c). The individual rings were computed by considering the proportion of the specific ring on the distance $\mathrm{dC}_{\mathrm{x}} \mathrm{I}_{\mathrm{xn}}-$ offset $_{\mathrm{xn}}$ (Fig. 3b, 3c).

Using the by now well-known weighting interpolation technique, an estimate of the ratios for $\mathrm{CS}_{\mathrm{x}}$ was possible:

ratio $_{X n i}=$ ratio $_{1 n i} \cdot\left(1-w_{1 \text { avg }}\right)+$ ratio $_{2 n i} \cdot w_{1 a v g}$

Thus, combining the two latter formulas the desired values of the ring-width distances $\mathrm{dP}_{\mathrm{xn}(\mathrm{i}-1)} \mathrm{P}_{\mathrm{xni}}$ can be retrieved for all ring boundaries and along all radii of $\mathrm{CS}_{\mathrm{x}}$. To guarantee that the sum of the new calculated ratios $_{X n i}$ for each $r_{n}$ matched the before computed distances $\mathrm{dC}_{\mathrm{x}} \mathrm{I}_{\mathrm{xn}}$-offset $\mathrm{x}_{\mathrm{xn}}$ the following constraint $\sum$ ratio $_{X n i}=1$ was used and a scaling needed to be done (Santini and Wagner 2010).

scaled_ratio $_{x n i}=\frac{\text { ratio }_{x n i}}{\sum_{i} \text { ratio }_{x n i}}$.

This scaling ensured that the constraint was not violated (Santini and Wagner 2010). This way, the reconstruction of the ring profiles of the cross section $\mathrm{CS}_{\mathrm{x}}$ was completed.

(V) The computation of the volume was done per annual growth year and calculated for individual sectors. The volume is first computed between pairs of adjacent cross sections and then added up for all pairs. The space between the two cross sections is divided in sectors delimited by two adjacent radii (Fig. 4). Each sector has a $1^{\circ}$
Fig. 4 Schematic illustration of the volume computations (step V)

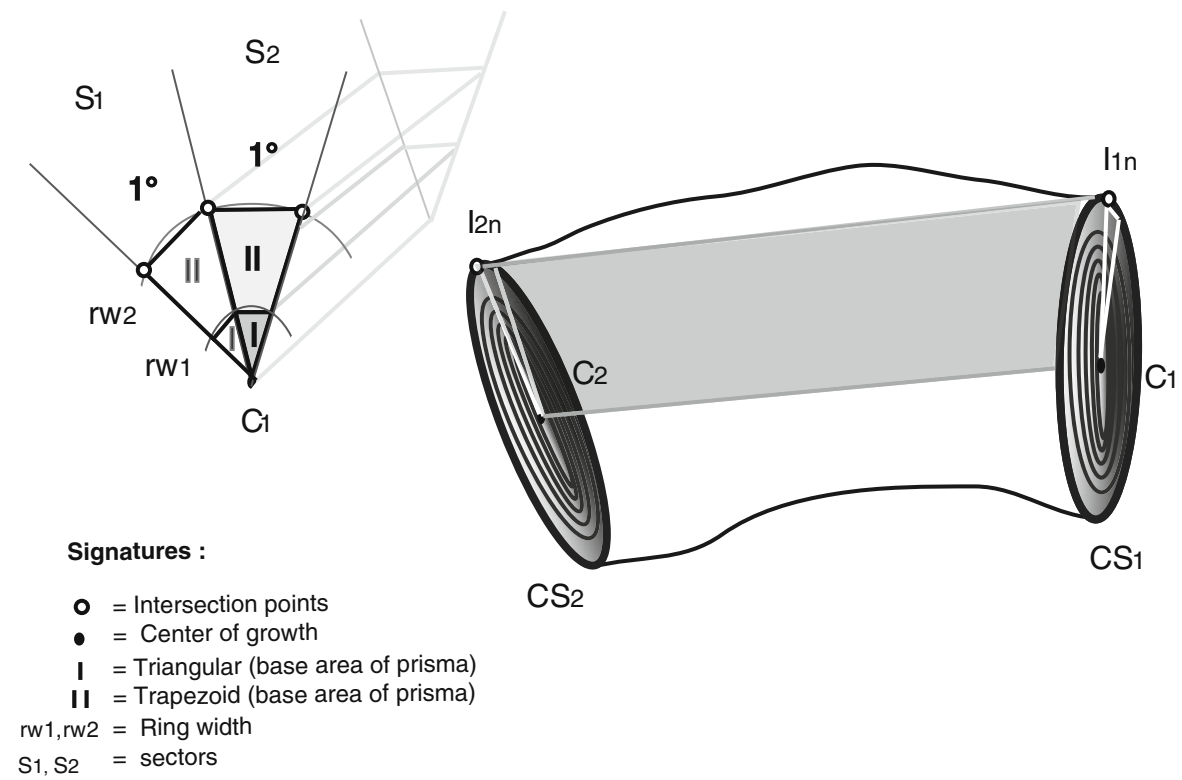


angle representing the same $1^{\circ}$ steps $\left(\mathrm{n}_{\text {total }}=360\right)$ for the ring calculations. Each sector was again subdivided into cells, whose boundaries within the sector are determined by two successive rings (Fig. 4). The base area of the first ring at the corresponding cross section was a triangle and therefore, a prismatic shape was approximated between two adjacent cross sections (Papula 2008). The base area of all the other rings was approximated by a trapezoid. For the total volume, the volumes of the individual cells were added to each other and this for every single growth year. Dependent on the growth year the increment portion of other years was subtracted. The error in the computation of the volume of each cell depends on the actual curvature of the rings. However, the default spacing between sectors is just $1^{\circ}$ and a straight line may thus well approximate the ring profile in such a restricted space. A second volume computation was implemented as a control of the volume computations approximating a cylinder between the cross sections by using the average of all radii and in addition the average distance between $\mathrm{C}_{1}$ and $\mathrm{C}_{2}$.

Tree stems and likewise roots have less tree rings at their tip compared to their base. In this study cross sections were measured approximately every $10 \mathrm{~cm}$, although additional sections were measured in the presence of high curvature. Along the growth axis the innermost annual ring(s) may disappear between two adjacent sections, because of decreasing age. As a consequence the growth layer of the innermost ring is present in the older cross section but not in the younger one. The end of such a growth layer was therefore represented as a cone between the two adjacent input cross sections. For this, the cross section with more rings had still a basal area for the disappearing ring whereas the cone of the growth layer tapered towards zero ending at the center point of the adjacent cross section (Santini and Wagner 2010). Thus, the interpolation algorithm between two cross sections is reconstructing only the last common ring.

The branching zone of roots features highly complex structures. These zones were difficult to interpolate and consequently a simplified approach was chosen. One of the roots was modeled as a continuous root and the second part was attached as a more or less flat cylinder starting on the surface of the continuous root representing the branching point.

The performance error of the model was difficult to assess as no empirical data about the annual volume or growth development existed. Therefore, different validation approaches were chosen - first based on the ring-width measurements and in addition based on the volume computations. The first approach compared the ring-width measurements of the input cross sections (based on the 2D interpolations between four input radii) with those achieved by the $3 \mathrm{D}$ interpolation. For every cross section the 360 radii were computed in step (I) of the interpolation procedure. To test the interpolation performance individual input cross sections were skipped (one section at a time) and recalculated. Thus, input cross sections $\mathrm{CS}_{1}$ and $\mathrm{CS}_{3}$ were used as input sections to recalculate $\mathrm{CS}_{2}$. Hence, the interpolation of ring-width profiles was then implemented at the corresponding site to this cross section and the two profiles compared with each other. Moreover, the series were computed with the new calculated growth origin $\mathrm{C}_{\mathrm{x}}$ (III) and with the original input growth center of the respective cross section, in order to control the computation of $\mathrm{C}_{\mathrm{x}}$.

The second validation approach was comparing the total volume computations of the roots. Volume was computed in two different ways with our model (for sectors; cylinders; (V)) and compared with the scanner reference model, which was the source model for the MATLAB program. The MATLAB program used the cross sections gained from the scanner model as input. In addition, the volume was computed using a changing number of intermediate cross sections $\left(\mathrm{CS}_{\mathrm{x}}\right)$.

To verify the data descriptive statistics for treering series were used (standard deviation, mean, variance). In addition, the MAE (mean absolute error) and the MAPE (mean absolute percentage error) were computed. They were computed for the entire data matrix (size $360 \mathrm{x}$; $i=$ number of rings) which was directly comparing the radii measured in $1^{\circ}$ steps. The MAE and the MAPE were also computed for the mean chronologies per cross section. Pearson's correlation was used to back up the relationship between the $2 \mathrm{D}$ and $3 \mathrm{D}$ tree-ring interpolations. 


\section{Results}

Ring-width data were successfully integrated into the 3D surface model and data gaps between the input cross sections were filled via 3D interpolation. Thus, the computation of tree-ring data was possible at any point within the 3D model and therefore, the annual reconstruction of the root development was realized (Fig. 5). These data of the 3D annual ring interpolations were compared with the ring profiles created by the $2 \mathrm{D}$ interpolations. Table 1 shows the comparison for the individual cross sections of two different roots. The mean annual ring width of each cross section resulting from the 3D interpolation widely agreed with the results gained from the 2D interpolations (Table 1). For root1 it deviated in average by $0.0054 \mathrm{~mm}$ and for Root 2 by $0.0140 \mathrm{~mm}$. When directly comparing the single radii (360) among each other, the MAE was always higher than if comparing the mean chronologies of the single cross sections. An exception of the generally robust reconstructions was cross section $11\left(\mathrm{CS}_{11}\right)$ of root1 having the highest reconstruction error of $0.1454 \mathrm{~mm}$ for the 360 single radii (MAPE of $34.4 \%$ ), and $0.1324 \mathrm{~mm}$ MAE for the mean chronologies (MAPE 20.9\%). Nevertheless, the mean ring-width remained similar $(0.554 \mathrm{~mm} 2 \mathrm{D}$ interpolation, $0.572 \mathrm{~mm} 3 \mathrm{D}$ interpolation). In contrast, the cross sections $\mathrm{CS}_{12}$ and $\mathrm{CS}_{13}$ of root2 had the smallest MAE for mean chronologies $0.0245 \mathrm{~mm}$ and $0.0314 \mathrm{~mm}$ respectively (Table 1). The lowest MAPE of $4.7 \%$ showed $\mathrm{CS}_{4}$ of root1, although the MAPE for the individual radii of $\mathrm{CS}_{4}$ was with $21.92 \%$ comparably high.

Figure 6 shows the ring profiles of the 2D and 3D interpolations in direct comparison for root1_CS 11 , root2_ $\mathrm{CS}_{6}$, and root $2 \mathrm{CS}_{12}$. The difference in the
Fig. 5 Model of root1 after the $3 \mathrm{D}$ interpolation of intermediate cross sections (four pro segment). With MATLAB it is also possible to connect the adjacent cross sections and therefore, to define the entire growth layer

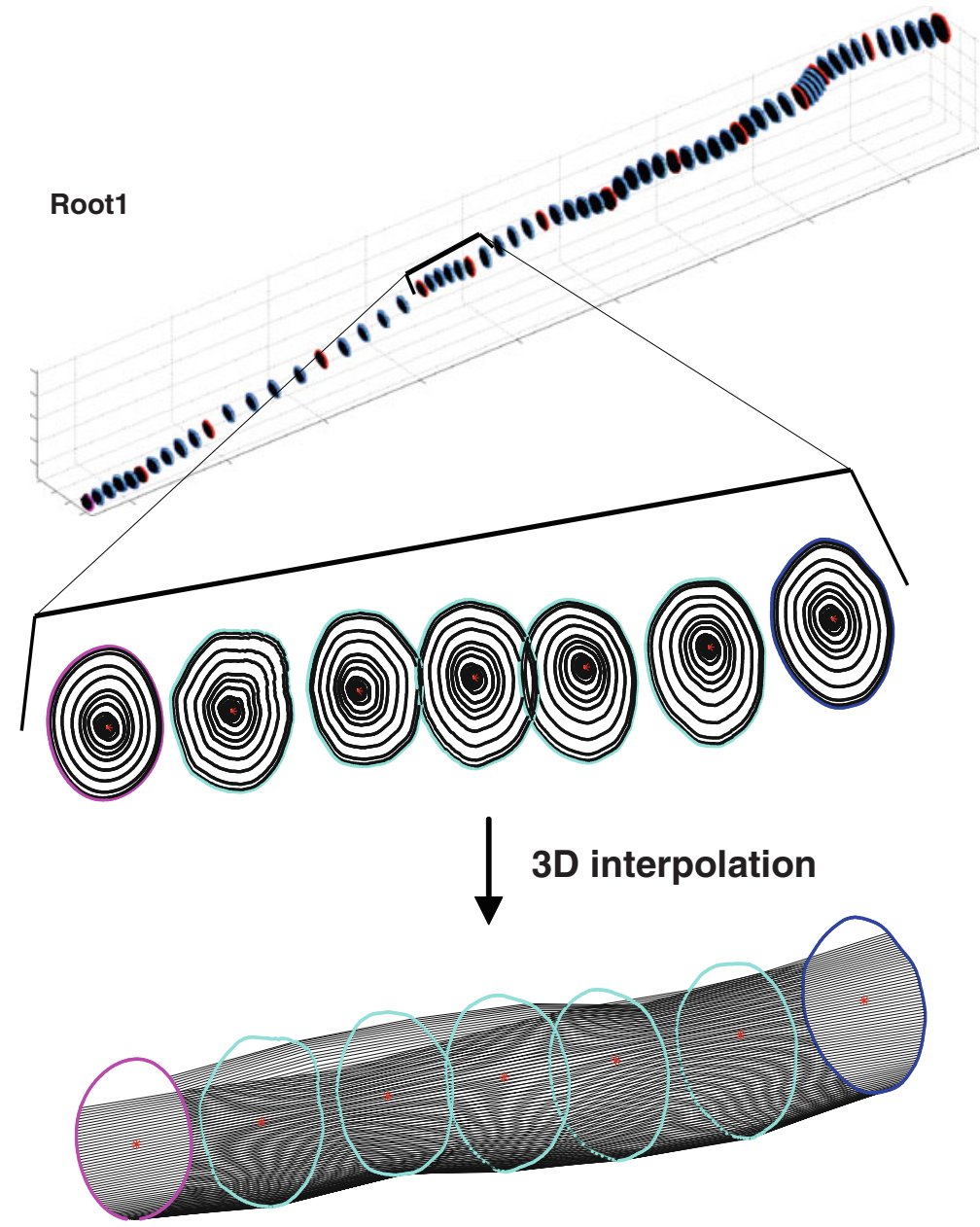


Table 1 Comparison of the main statistical values of the ringwidth data resulting from the $2 \mathrm{D}$ and $3 \mathrm{D}$ interpolation on all cross sections of root1 and root2 (Mean Mean ring width; StandDev standard deviation; MAE $1^{\circ}$ steps Mean absolute error for the $3601^{\circ}$ steps; MAE (MC) Mean absolute error for the mean tree-ring chronologies; MAPE Mean absolute percentage error)

\begin{tabular}{|c|c|c|c|c|c|c|c|c|}
\hline Root 1 & & $\begin{array}{l}\text { Mean } \\
(\mathrm{mm})\end{array}$ & $\begin{array}{l}\text { StandDev } \\
(\mathrm{mm})\end{array}$ & Variance & $\begin{array}{l}\text { MAE } 1^{\circ} \text { steps } \\
(\mathrm{mm})\end{array}$ & $\begin{array}{l}\text { MAPE } 1^{\circ} \text { steps } \\
(\%)\end{array}$ & $\begin{array}{l}\text { MAE }(\mathrm{MC}) \\
(\mathrm{mm})\end{array}$ & $\begin{array}{l}\text { MAPE (MC) } \\
(\%)\end{array}$ \\
\hline $\mathrm{CS} 2$ & $\begin{array}{l}\text { Interpolated 2D } \\
\text { Interpolated 3D }\end{array}$ & $\begin{array}{l}0.832 \\
0.829\end{array}$ & $\begin{array}{l}0.109 \\
0.096\end{array}$ & $\begin{array}{l}0.0162 \\
0.0152\end{array}$ & 0.0834 & 11.0363 & 0.0457 & 5.9084 \\
\hline $\mathrm{CS} 3$ & $\begin{array}{l}\text { Interpolated 2D } \\
\text { Interpolated } 3 \mathrm{D}\end{array}$ & $\begin{array}{l}0.794 \\
0.803\end{array}$ & $\begin{array}{l}0.099 \\
0.088\end{array}$ & $\begin{array}{l}0.0147 \\
0.0090\end{array}$ & 0.1093 & 15.1672 & 0.0447 & 5.9413 \\
\hline $\mathrm{CS} 4$ & $\begin{array}{l}\text { Interpolated 2D } \\
\text { Interpolated 3D }\end{array}$ & $\begin{array}{l}0.749 \\
0.748\end{array}$ & $\begin{array}{l}0.159 \\
0.111\end{array}$ & $\begin{array}{l}0.0330 \\
0.0171\end{array}$ & 0.1266 & 21.9244 & 0.0352 & 4.6732 \\
\hline CS5 & $\begin{array}{l}\text { Interpolated 2D } \\
\text { Interpolated 3D }\end{array}$ & $\begin{array}{l}0.701 \\
0.719\end{array}$ & $\begin{array}{l}0.115 \\
0.090\end{array}$ & $\begin{array}{l}0.0186 \\
0.0113\end{array}$ & 0.0926 & 19.9232 & 0.0314 & 5.5581 \\
\hline CS6 & $\begin{array}{l}\text { Interpolated 2D } \\
\text { Interpolated 3D }\end{array}$ & $\begin{array}{l}0.716 \\
0.712\end{array}$ & $\begin{array}{l}0.148 \\
0.078\end{array}$ & $\begin{array}{l}0.0310 \\
0.0096\end{array}$ & 0.0863 & 17.8709 & 0.0442 & 6.5840 \\
\hline CS7 & $\begin{array}{l}\text { Interpolated 2D } \\
\text { Interpolated } 3 \mathrm{D}\end{array}$ & $\begin{array}{l}0.685 \\
0.686\end{array}$ & $\begin{array}{l}0.140 \\
0.061\end{array}$ & $\begin{array}{l}0.0328 \\
0.0046\end{array}$ & 0.1047 & 19.3232 & 0.0669 & 8.4273 \\
\hline $\mathrm{CS} 8$ & $\begin{array}{l}\text { Interpolated 2D } \\
\text { Interpolated 3D }\end{array}$ & $\begin{array}{l}0.617 \\
0.616\end{array}$ & $\begin{array}{l}0.083 \\
0.067\end{array}$ & $\begin{array}{l}0.0100 \\
0.0057\end{array}$ & 0.0800 & 17.2330 & 0.0378 & 7.54806 \\
\hline CS9 & $\begin{array}{l}\text { Interpolated 2D } \\
\text { Interpolated 3D }\end{array}$ & $\begin{array}{l}0.572 \\
0.586\end{array}$ & $\begin{array}{l}0.114 \\
0.070\end{array}$ & $\begin{array}{l}0.0161 \\
0.0060\end{array}$ & 0.0962 & 19.1686 & 0.0538 & 6.8570 \\
\hline CS10 & $\begin{array}{l}\text { Interpolated 2D } \\
\text { Interpolated 3D }\end{array}$ & $\begin{array}{l}0.538 \\
0.526\end{array}$ & $\begin{array}{l}0.083 \\
0.058\end{array}$ & $\begin{array}{l}0.0094 \\
0.0038\end{array}$ & 0.0899 & 18.5391 & 0.0621 & 10.8879 \\
\hline CS11 & $\begin{array}{l}\text { Interpolated 2D } \\
\text { Interpolated 3D }\end{array}$ & $\begin{array}{l}0.554 \\
0.572\end{array}$ & $\begin{array}{l}0.128 \\
0.065\end{array}$ & $\begin{array}{l}0.0223 \\
0.0053\end{array}$ & 0.1454 & 34.3984 & 0.1324 & 20.8988 \\
\hline CS12 & $\begin{array}{l}\text { Interpolated 2D } \\
\text { Interpolated 3D }\end{array}$ & $\begin{array}{l}0.510 \\
0.506\end{array}$ & $\begin{array}{l}0.096 \\
0.060\end{array}$ & $\begin{array}{l}0.0128 \\
0.0047\end{array}$ & 0.1032 & 19.9208 & 0.0757 & 12.3165 \\
\hline CS13 & $\begin{array}{l}\text { Interpolated 2D } \\
\text { Interpolated 3D }\end{array}$ & $\begin{array}{l}0.494 \\
0.499\end{array}$ & $\begin{array}{l}0.079 \\
0.070\end{array}$ & $\begin{array}{l}0.0075 \\
0.0071\end{array}$ & 0.0834 & 17.9481 & 0.0568 & 9.3686 \\
\hline \multicolumn{9}{|l|}{ Root 2} \\
\hline $\mathrm{CS} 2$ & $\begin{array}{l}\text { Interpolated 2D } \\
\text { Interpolated 3D }\end{array}$ & $\begin{array}{l}1.197 \\
1.176\end{array}$ & $\begin{array}{l}0.266 \\
0.206\end{array}$ & $\begin{array}{l}0.1101 \\
0.0718\end{array}$ & 0.1495 & 14.3105 & 0.0984 & 9.4385 \\
\hline $\mathrm{CS} 3$ & $\begin{array}{l}\text { Interpolated 2D } \\
\text { Interpolated 3D }\end{array}$ & $\begin{array}{l}1.135 \\
1.142\end{array}$ & $\begin{array}{l}0.105 \\
0.116\end{array}$ & $\begin{array}{l}0.0195 \\
0.0218\end{array}$ & 0.0952 & 10.7462 & 0.0606 & 7.3187 \\
\hline $\mathrm{CS} 4$ & $\begin{array}{l}\text { Interpolated 2D } \\
\text { Interpolated } 3 \mathrm{D}\end{array}$ & $\begin{array}{l}1.038 \\
1.025\end{array}$ & $\begin{array}{l}0.090 \\
0.065\end{array}$ & $\begin{array}{l}0.0095 \\
0.0054\end{array}$ & 0.1013 & 11.6436 & 0.067 & 7.6624 \\
\hline CS5 & $\begin{array}{l}\text { Interpolated 2D } \\
\text { Interpolated 3D }\end{array}$ & $\begin{array}{l}0.958 \\
0.946\end{array}$ & $\begin{array}{l}0.072 \\
0.072\end{array}$ & $\begin{array}{l}0.0058 \\
0.0065\end{array}$ & 0.0821 & 11.0699 & 0.0446 & 5.6782 \\
\hline CS6 & $\begin{array}{l}\text { Interpolated 2D } \\
\text { Interpolated 3D }\end{array}$ & $\begin{array}{l}0.925 \\
0.943\end{array}$ & $\begin{array}{l}0.105 \\
0.056\end{array}$ & $\begin{array}{l}0.0142 \\
0.0042\end{array}$ & 0.0977 & 12.8154 & 0.0507 & 6.3849 \\
\hline CS7 & $\begin{array}{l}\text { Interpolated 2D } \\
\text { Interpolated 3D }\end{array}$ & $\begin{array}{l}0.859 \\
0.854\end{array}$ & $\begin{array}{l}0.064 \\
0.070\end{array}$ & $\begin{array}{l}0.0068 \\
0.0062\end{array}$ & 0.1042 & 13.7931 & 0.0506 & 5.9729 \\
\hline CS8 & $\begin{array}{l}\text { Interpolated 2D } \\
\text { Interpolated 3D }\end{array}$ & $\begin{array}{l}0.855 \\
0.866\end{array}$ & $\begin{array}{l}0.130 \\
0.095\end{array}$ & $\begin{array}{l}0.0229 \\
0.0140\end{array}$ & 0.1065 & 18.1576 & 0.0643 & 12.5788 \\
\hline CS9 & $\begin{array}{l}\text { Interpolated 2D } \\
\text { Interpolated 3D }\end{array}$ & $\begin{array}{l}0.826 \\
0.846\end{array}$ & $\begin{array}{l}0.094 \\
0.061\end{array}$ & $\begin{array}{l}0.0100 \\
0.0046\end{array}$ & 0.1032 & 16.7858 & 0.0399 & 8.9450 \\
\hline CS10 & $\begin{array}{l}\text { Interpolated 2D } \\
\text { Interpolated 3D }\end{array}$ & $\begin{array}{l}0.792 \\
0.801\end{array}$ & $\begin{array}{l}0.121 \\
0.049\end{array}$ & $\begin{array}{l}0.0174 \\
0.0026\end{array}$ & 0.0990 & 14.8814 & 0.0312 & 7.4537 \\
\hline CS11 & $\begin{array}{l}\text { Interpolated 2D } \\
\text { Interpolated 3D }\end{array}$ & $\begin{array}{l}0.696 \\
0.715\end{array}$ & $\begin{array}{l}0.060 \\
0.070\end{array}$ & $\begin{array}{l}0.0043 \\
0.0060\end{array}$ & 0.0815 & 13.9551 & 0.0283 & 7.6528 \\
\hline CS12 & Interpolated 2D & 0.655 & 0.057 & 0.0189 & 0.0621 & 12.1580 & 0.0245 & 6.5448 \\
\hline
\end{tabular}


Table 1 (continued)

\begin{tabular}{|c|c|c|c|c|c|c|c|c|}
\hline \multicolumn{2}{|l|}{ Root 1} & \multirow{2}{*}{$\begin{array}{l}\begin{array}{l}\text { Mean } \\
(\mathrm{mm})\end{array} \\
0.670\end{array}$} & \multirow{2}{*}{$\begin{array}{c}\begin{array}{l}\text { StandDev } \\
(\mathrm{mm})\end{array} \\
0.051\end{array}$} & \multirow{2}{*}{$\begin{array}{c}\text { Variance } \\
0.0028\end{array}$} & \multirow{2}{*}{$\begin{array}{l}\text { MAE } 1^{\circ} \text { steps } \\
(\mathrm{mm})\end{array}$} & \multirow{2}{*}{$\begin{array}{l}\text { MAPE } 1^{\circ} \text { steps } \\
(\%)\end{array}$} & \multirow{2}{*}{$\begin{array}{l}\text { MAE }(\mathrm{MC}) \\
(\mathrm{mm})\end{array}$} & \multirow{2}{*}{$\begin{array}{l}\text { MAPE (MC) } \\
(\%)\end{array}$} \\
\hline & Interpolated 3D & & & & & & & \\
\hline CS13 & $\begin{array}{l}\text { Interpolated 2D } \\
\text { Interpolated 3D }\end{array}$ & $\begin{array}{l}0.594 \\
0.596\end{array}$ & $\begin{array}{l}0.070 \\
0.046\end{array}$ & $\begin{array}{l}0.0056 \\
0.0025\end{array}$ & 0.0648 & 13.7492 & 0.0314 & 8.5417 \\
\hline $\mathrm{CS} 14$ & $\begin{array}{l}\text { Interpolated 2D } \\
\text { Interpolated 3D }\end{array}$ & $\begin{array}{l}0.551 \\
0.574\end{array}$ & $\begin{array}{l}0.078 \\
0.043\end{array}$ & $\begin{array}{l}0.0074 \\
0.0023\end{array}$ & 0.0712 & 14.3729 & 0.04140 & 10.1619 \\
\hline CS15 & $\begin{array}{l}\text { Interpolated 2D } \\
\text { Interpolated 3D }\end{array}$ & $\begin{array}{l}0.495 \\
0.521\end{array}$ & $\begin{array}{l}0.054 \\
0.039\end{array}$ & $\begin{array}{l}0.0034 \\
0.0019\end{array}$ & 0.0698 & 17.2460 & 0.0389 & 12.6175 \\
\hline
\end{tabular}

performance for the three cross sections is clearly visible. Especially the shift of the growth origin for section root1_ $\mathrm{CS}_{11}$ is evident. The mean ring-width series are also exemplarily shown for the same three cross sections (Fig. 6). The differences in the reconstruction performance are also visible here. In general, the 2D and 3D interpolations showed the same growth patterns. Even for $\mathrm{CS}_{11}$ with the shifted growth origin the growth pattern was still preserved in the mean chronologies.

Table 2 shows the average MAPE for root1 and root2 in dependence on the growth center used. The average MAPE for the comparison of the 360 radii of all 12 tested cross sections of root1 was $19.4 \%$ and for all 14 sections of $\operatorname{root} 216.9 \%$ (Table 2). The MAPE computed for the mean chronologies of the individual roots were in average $8.75 \%$ for both roots. In general, the results for root 2 were more accurate. The average MAPE for the mean chronologies calculated with the $\mathrm{CS}_{\mathrm{x}}$ were by $0.39 \%$ slightly higher for root1 (by $0.55 \%$ slightly higher for root 2 ) than those done with the input growth center. For the MAPE of the single radii the impact of the growth center used was more evident. Here the average MAPE for interpolations with $\mathrm{C}_{\mathrm{x}}$ were by $5.39 \%$ greater for root1 and by $3.96 \%$ greater for root 2 compared to calculations with the input growth center. The high correlation coefficient especially for root2 $(r=$ 0.9683 ) emphasized the strong relationship between the $2 \mathrm{D}$ and $3 \mathrm{D}$ interpolations. Of course data were dependent on each other and therefore, a high correlation coefficient was expected; nevertheless the interpolation performance was further proofed.

The total and annually resolved volume computations are presented in Table 3. For both roots the MATLAB model resulted in a greater volume compared to the scanner and the cylinder model.
The cylinder approximation was underestimating the volume compared to the scanner model. The higher accuracy of the ring reconstructions of root 2 was also shown in a smaller deviation in volume for root2 (Table 3). The calculated offset was always between $5 \%$ and $6 \%$ (Table 4), which is comparable with the offset of the scanner model.

The sum of the annual volume computation for root1 was $184,302 \mathrm{~mm}^{3}$, only $0.54 \%$ greater than the volume calculations of the reference model $\left(182,968 \mathrm{~mm}^{3}\right)$. For root 2 the sum of the annual volume computation was $439,900 \mathrm{~mm}^{3}$, which is $2.2 \%$ less than the volume computations of the reference model.

When the number of the calculated intermediate cross sections $\left(\mathrm{CS}_{\mathrm{x}}\right)$ was changed, the computed volume deviated slightly (Table 4 ). The deviations of root1 showed continuous increases with the number of intermediate cross sections. This was not true for root2, where the deviations increased when using two, four and six intermediate sections, but decreased from six to ten intermediate sections.

\section{Discussion}

The tool developed was able to calculate annual ring data at any point within the 3D model. Hence, a model was developed, which allows for annual growth analyses and annual volume computations. The question is if the model is a robust and reliable tool for a realistic reconstruction of root development. The verification of the annual volume data is problematic since no empirical data of the annual volume distribution were available. However, total volume computations and ring-width data were used to validate the model. 
Fig. 6 Three reconstructed cross sections showing their spatial context, their mean chronologies and the deviations occurring between 3D and $2 \mathrm{D}$ interpolations
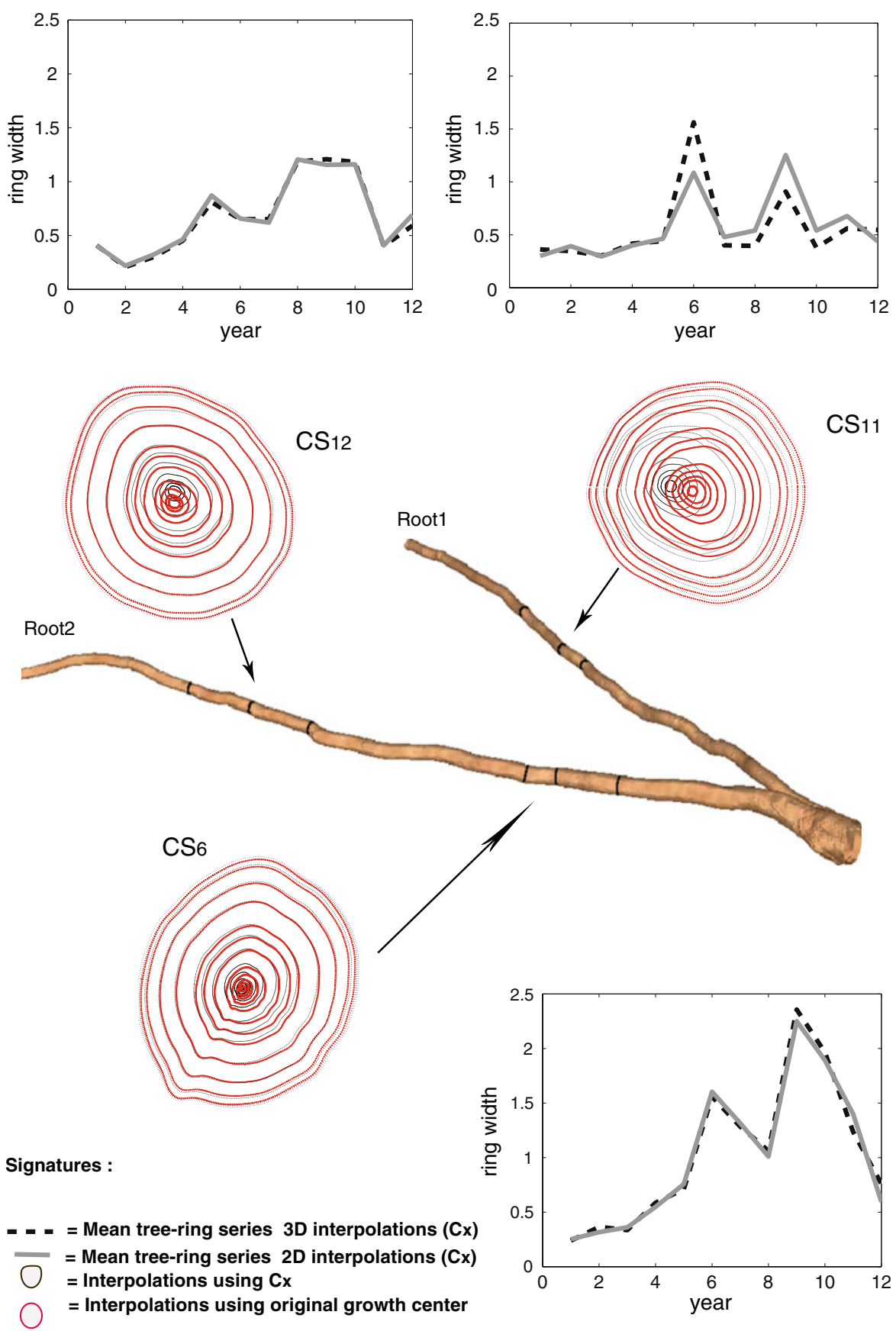

The MATLAB volume computations (sector model) for root1 were about $6.5 \%$ (root2 about $3.7 \%$ ) greater than the volumes of the scanned reference model (Table 4). These results were promising, but it has to be considered that the scanner model already showed an offset by about 5 to $7 \%$ from the actual volume. A primary question was if these errors propagated within the model. There is evidence that this was not the case, because the offset, which was included in each of the models remained stable, independent of the calculation technique used (Table 4). The offset ranged from 5.5 to $6.1 \%$. Due to the stable ratios between offset and total volume the presented model was able to provide predictable volume data. When subtracting the offset 
Table 2 Comparison of tree-ring profiles computed once with the original center point of the input data and once with the new computed center point $\mathrm{C}_{\mathrm{x}}$ (Pearson's correlation coefficient, MAPE and for single radii $\left(1^{\circ}\right)$ and (MC) mean chronologies)

\begin{tabular}{lllll}
\hline & & Correlation Coeff & $\begin{array}{l}\text { MAPE } \\
(\%) 1^{\circ} \text { steps }\end{array}$ & $\begin{array}{l}\text { MAPE } \\
(\%)(M C)\end{array}$ \\
\hline root1 & $\mathrm{C}_{\mathrm{X}}$ & 0.8924 & 19.3711 & 8.7474 \\
& Input center & 0.9078 & 13.9775 & 8.3537 \\
root2 & $\mathrm{C}_{\mathrm{X}}$ & 0.9683 & 16.8561 & 8.7467 \\
& Input center & 0.9732 & 12.8977 & 8.1937 \\
\hline
\end{tabular}

from the MATLAB-sector model, the volume matches the total volume of the scanner models including the offset. Therefore, we can conclude that the volume of the sector method was within the error range of the scanner (5-7\%). This deviation in volume is a convincing result for a model, which is always an approximation to reality.

Volume computations were deviating slightly with changing number of intermediate cross sections calculated. For root1 the offset in volume increased with the number of sections. In general one would expect that the interpolations will gain in accuracy with increasing number of sections. However, this was not necessarily the case as all intermediate sections $\left(C_{X}\right)$ were calculated independent of each other. Therefore, we believe that no matter how many intermediate sections are calculated $\left(\mathrm{C}_{\mathrm{X}}\right)$ their accuracy is dependent on the position where the section is calculated rather than the amount of sections. This can be examined when looking at Fig. 5 an extreme deformation of an input section will influence the structure of $\mathrm{C}_{\mathrm{X}}$ due to the applied weight, but a deformation of the circumference of $\mathrm{C}_{\mathrm{X}}$ was having only local impact on the section itself. Hence, when cutting the cross sections out of the scanner model it is already necessary to check if the circumference is representative for the true circumference or if artifacts occur due to bark sticking out or smaller roots. The deviation in volume was therefore rather a result of the root structure and the position where the cut was calculated than of the number of sections (Table 4).

In general, the root size has to be considered for the error computation. A very small overestimation in diameter on small roots can give a high percentage of error for the volume computations whereas the same absolute error may give a smaller percentage error for larger roots. The roots used for the presented study were rather small $(1.6$ and $1.8 \mathrm{~cm})$.

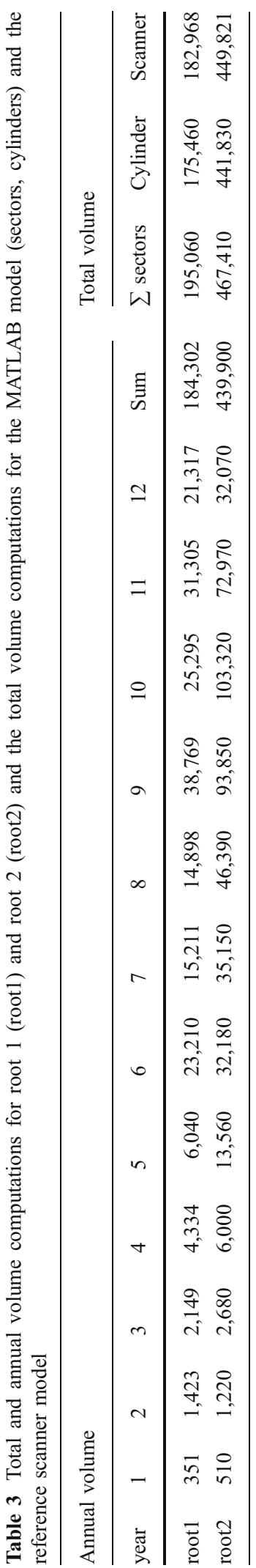


Table 4 Deviations for volume computation techniques in comparison to the reference scanner model and for a varying amount of intermediate cross sections calculated between $\mathrm{C}_{1}$ and $\mathrm{C}_{2}$ given in percent (\%)

\begin{tabular}{lllllllll}
\hline No of CS & 2 & 4 & 6 & 8 & 10 & STD & Mean & Variance \\
\hline root1 & & & & & & & & \\
$\quad$ Sectors & 6.31 & 6.45 & 6.61 & 6.58 & 6.80 & 0.1820 & 6.61 & 0.0145 \\
Cylinder & 3.45 & 4.00 & 4.10 & 4.13 & 4.14 & 0.2955 & 4.09 & 0.0005 \\
Offset_cylinder & 5.84 & 5.87 & 5.9 & 5.89 & 5.90 & 0.0241 & 5.89 & 0.0001 \\
Offset_sectors & 5.49 & 5.51 & 5.52 & 5.53 & 5.53 & 0.0139 & 5.52 & 0.0000 \\
root2 & & & & & & & & \\
Sectors & 3.52 & 3.63 & 3.91 & 3.65 & 3.71 & 0.1438 & 3.73 & 0.0182 \\
Cylinder & 2.07 & 1.83 & 1.78 & 2.01 & 2.05 & 0.1344 & 1.91 & 0.0213 \\
Offset_cylinder & 6.09 & 6.09 & 6.11 & 6.10 & 6.11 & 0.0116 & 6.10 & 0.0000 \\
Offset_sectors & 5.88 & 5.88 & 5.88 & 5.89 & 5.89 & 0.0054 & 5.88 & 0.0000 \\
\hline
\end{tabular}

Although we are confident that our volume computations are in a predictable range (see above) the computations were done by approximating prismatic shapes, which is not truly the case (Fig. 4). We believe that our method reflects a reliable approximation, because each sector had only an angle of $1^{\circ}$ and thus was rather small. If necessary the angle could be further reduced. One critical point though was that the neglected portion may vary between the rings an especially between inner and outer most rings. Usually we would expect an underestimation of volume, because the portion neglected at the upper part of the prism should be larger than the one added at the lower part of the prism. Here, the curvature of the tree-ring structure plays a role. When a cyclic ring form is assumed, for a $0.5 \mathrm{~mm}$ growth ring the error due to the approximation increases with increasing distance to the growth center (e.g., distance $1 \mathrm{~mm}$ : $0.00000211 \mathrm{~mm}^{2}$; distance $1 \mathrm{~cm}$ : $0.00000454 \mathrm{~mm}^{2}$; distance $2 \mathrm{~cm}: 0.00000897 \mathrm{~mm}^{2}$ ). At cross sections with extreme deformations overestimations might occur. Another possible explanation for overestimations might be that the prismatic shapes did not consider the root tapering after branching points in a sufficient (Soethe et al. 2007). However, the reason for a general overestimation is not fully understood and requires further investigations.

The tree-ring analyses allowed an additional check for our model. When comparing the MAPE of the 2D and the $3 \mathrm{D}$ interpolations the MAPE for the single radii were in average $19.37 \%$ for root 1 and $16.86 \%$ for root2, which is quite high. Nevertheless, the results for the mean chronologies were promising (average MAPE $8.75 \%$ for both roots).

Analyses of the positions of the individual cross sections may help to understand the differences in the interpolation performances. $\mathrm{CS}_{11}$ of root1 for example showed the most pronounced deviations with a MAPE of $20.9 \%$ for $\mathrm{MC}$ (Fig. 6). In contrast, $\mathrm{CS}_{12}$ of root2 was a good approximation to reality with a MAPE of $6.54 \%$ for MC. When their positions within the root system were analyzed (Fig. 6) $\mathrm{CS}_{12}$ was positioned at a relatively straight part of the root although the distance between the input cross sections was wider. $\mathrm{CS}_{6}$ of root2 was also a quite robust reconstruction although showing similar conditions as root1_CS $\mathrm{S}_{11}$.

Although some greater reconstruction errors occurred the growth trends were clearly preserved in all mean chronologies and also in all the chronologies of the individual radii. This makes the model an innovative and applicable tool for tree-ring analyses. The fact that mean chronologies are widely used for tree-ring analyses (Cook and Kairiukstis 1990) and also for biomass equations (Pearson et al. 1987) strengthened this assumption.

The model is based on a limited data set of 4 radii per cross section, the outer structure of the root at the input cross sections and the new calculated cross sections. Therefore, certain assumptions were required for the interpolation of the missing data. These assumptions can also be error sources if they do not conform to reality. The calculation of the center points $\mathrm{C}_{\mathrm{x}}$ was based on the assumption that $\mathrm{C}_{\mathrm{x}}$ is close to the intersection lines with the plane (I). The assumption was tested by comparing the ring profiles once calculated with the new center $C_{x}$ and once with the measured input growth center. As expected computations were more accurate when the growth centers of the input data were used. Nevertheless, the deviations between the two approaches showed only slight differences for MC by $0.39 \%$ for 
root 1 and $0.55 \%$ for root 2 of the MAPE. This strengthened the assumption that the calculation of the $C_{X}$ is widely applicable. For the individual radii the deviations were clearer dependent on the growth center used (root1 MAPE deviated by $5.39 \%$ ). Therefore, an additional check of the calculated growth center is required for critical sections e.g., with a stronger inclination. For other cross sections minor deviations were also reached for single radii $\left(\mathrm{CS}_{2}\right.$ root1, $\mathrm{CS}_{3}$ root2) which also strengthened the assumption made and the applicability of the model.

The changing growth axis might play a crucial role in several parts of the procedure, for instance resulting in non-parallel input cross sections. In general, the interpolation results were improved, when input cross sections were parallel to each other and the shape of the root quite straight (Fig. 6). This showed the importance of the raw data. Clearly, for straighter parts of the root less input cross sections were sufficient whereas it was necessary in high curved regions to set additional cuts. The interpolations were more accurate when more input data were available ( $\mathrm{Zu}$ Castell et al. 2005). However, a compromise had to be made between a realistic workload and a sufficient number of input sections for higher accuracy. When the cross sections for ring-width measurements were set carefully the tool developed was a robust instrument for 3D root reconstruction. For all cross sections except cross section root $\mathrm{CS}_{11}$ the results for the $\mathrm{MC}$ were in a convincing range.

Some of the possible error sources such as the distance and angle between input sections and the structure of the surface model can be further improved in future. Although for single sections some bigger deviations to reality occurred (root1 $\mathrm{CS}_{11}$ ) the error may be caused by the input data rather than the algorithm. The curvature of the 3D surface model and the raw data turned out to be a critical point in these terms. Possible solutions to improve the method further would be to develop more complex weights for the interpolation algorithm which consider the rotation between two input cross sections in more detail or for highly deformed sections to measure additional input cross sections.

Models are always approximations to the reality and therefore, certain compromises have to be accepted. However, the model presented was able to generate convincing ring profiles and volume data, as the MAPE for the MC was in average $8.75 \%$ and the volume deviated by up to $6.6 \%$. Although the error for individual tree-ring radii was higher (MAPE 19.37\%) the tree-ring series were clearly showing the same growth pattern. Therefore, we are confident that the produced data will allow for complex tree-ring analyses within a root system. The uniqueness of the data set fully justifies the amount of work.

\section{Conclusion}

The coarse-root development model presented is able to shed light on annual root development and especially on volume allocation within the root system. Such data was not available before and can help answering crucial questions in terms of biomass allocation and anchorage processes.

A model was developed which is reconstructing the 3D development of a root system on an annual basis. The measurements and prearrangements of the input data (ring-width measurements, scanning, modeling) are time demanding, which is typical for coarse root studies (Tobin et al. 2007). Nevertheless, we are convinced that it is worth it the effort. The data acquired from this new method have never been available before and can answer fundamental questions about root development. Although this model was applied for roots it can easily be transferred to the aboveground part of trees allowing for complex analyses of allocation and moreover, influence of root on stem development.

However, when applying the model, some restrictions have to be considered. Laser scanning is limited when the root systems exceed a certain complexity, because the laser beam will not reach all parts of a root system hidden by other roots. Thus, we highly recommend the model especially for younger trees and those who have protruding root-systems. Higher deformations may result in a higher error or to avoid these errors in additional workload.

With the presented model a tool was developed to analyze individual reactions of root systems to specific environmental conditions. In future, the approach will be extended to an entire tree to quantify the relationships between above- and belowground growth patterns. This is fundamental for understanding allocation and biomass development over time, which plays a key question for the global carbon budget. The workload for the aboveground part is expected to be comparable low and the reconstructions more robust due to the simpler shapes. 
The model presented here has high potential to be upgraded and linked with other models for instance, topological models (Danjon and Reubens 2008). The Laser ScanArm applied consists of a tactile probe for point measurements. This could be used for additional topological measurements comparable to the digitizer as it was already successfully applied (Danjon et al. 1999; Oppelt et al. 2000).

Due to the complexity of the problems in root development, biomass etc. a combination of existing models is advisable (Tobin et al. 2007). Simulations are not possible with the presented model but a combination with predictive models is conceivable and by supply data of the past growth may act as a control for these models.

Acknowledgements The authors wish to thank the Swiss National Science Foundation (SNF) for funding the project (No.: 200021-113450). Furthermore, the authors are grateful to Dr. J. Grießinger for helpful comments on the final version of the manuscript.

\section{References}

Bert D, Danjon F (2006) Carbon concentration variations in the roots, stem and crown of mature Pinus pinaster (Ait.). For Ecol Manag 222:279-295. doi:10.1016/j.foreco.2005.10.030

Brunner I, Godbold DL (2007) Tree roots in a changing world. J For Res 12:78-82. doi:10.1007/s10310-006-0261-4

Cook ER, Kairiukstis A (eds) (1990) Methods of dendrochronolgy - applications in the environmental science. Kluwer, Dordrecht

Danjon F, Reubens B (2008) Assessing and analyzing 3D architecture of woody root systems, a review of methods and applications in tree and soil stability, resource acquisition and allocation. Plant Soil 303:1-34. doi:10.1007/s11104-007-9470-7

Danjon F, Bert D, Godin C, Trichet P (1999) Structural root architecture of 5-year-old Pinus pinaster measured by 3D digitising and analysed with AMAPmod. Plant Soil 217:49-63. doi:10.1023/A:1004686119796

Drexhage M, Gruber F (1999) Above- and below-stump relationships for Picea Abies: estimating root system biomass from breast-height diameter. Scand J For Res 14:328-333. doi:10.1080/02827589950152647

Dupuy L, Fourcaud T, Lac P, Stokes A (2007) A generic 3D finite element model of tree anchorage integrating soil mechanics and real root system architecture. Am J Bot 94:1506-1514

FARO Technologies Inc., 2010. http://www.faro.com/

Genet H, Bréda N, Durfrêne E (2009) Age-related variation in carbon allocation at tree and stand scales in beech (Fagus sylvatica L.) and sessile oak (Quercus petraea (Matt.) Liebl.) using a chronosequence approach. Tree Physiol 30:177-192. doi:10.1093/treephys/tpp105
Heimann M, Reichstein M (2008) Terrestrial ecosystem carbon dynamics and climate feedbacks. Nature 45:289-292. doi:10.1038/nature06591

Henderson R, Ford ED, Renshaw E, Deans JD (1983) Morphology of the structural root system of sitka spruce 2. Computer simulation of rooting pattern. Forestry 56 : $121-135$

Jourdan C, Rey H (1997) Architecture and development of the oil-palm (Elaeis guineensis Jacq.) root system. Plant Soil 189:33-48. doi:10.1023/A:1004290024473

King JS, Giardina CP, Pregitzer KS, Friend AL (2007) Biomass partitioning in red pine (Pinus resinosa) along a chronosequence in the Upper Peninsula of Michigan. Can J For Res 37:93-102. doi:10.1139/X06-217

Lecompte F, Ozier-Lafontaine H, Pagès L (2001) The relationships between static and dynamic variables in the description of root growth. Consequences for field interpretation of rooting variability. Plant Soil 236:19-31. doi:10.1023/A:1011924529885

Le Roux Y, Pagès L (1994) Développement et polymorphisme racinaires chez de jeunes semis d'hévéa (Hevea brasiliensis). Can J Bot 72:924-932

Lichti D, Gordon S, Tipdecho T (2005) Error models and propagation in directly georeferenced terrestrial laser scanner networks. J Surv Eng ASCE 131(4):135-142. doi:10.1061/(ASCE)0733-9453(2005)131:4(135)

Oppelt A, Kurth W, Dzierzon H, Jentschke G, Godbold D (2000) Structure and fractal dimensions of root systems of four co-occurring fruit tree species from Botswana. Ann For Sci 57:463-475. doi:10.1051/ forest:2000135

Pagès L, Aries F (1988) SARAH: modèle de simulation de la croissance, du développement et de architecture des systèmes racinaires. Agronomie 8:889-896

Pagès L, Bengough AG (1997) Modelling minirhizotron observations to test experimental procedures. Plant Soil 189:81-89. doi:10.1023/A:1004288430467

Pagès L, Vercambre G, Drouet JL, Lecompte F, Collet C, Le Bot J (2004) Root Typ: a generic model to depict and analyse the root system architecture. Plant Soil 258:103119. doi:10.1023/B:PLSO.0000016540.47134.03

Papula L (2008) Mathematik für Ingenieure und Naturwissenschaftler (Band 1). Vieweg + Teubner Verlag, Wiesbaden

Pearson JA, Knight DH, Fahey TJ (1987) Biomass and nutrient accumulation during stand development in Wyoming Lodgepole pine forests. Ecology 68:1966-1973. doi:10.2307/1939887

Pradal C, Boudon F, Nouguier C, Chopard J, Godin C (2009) PlantGL: a python-based geometric library for 3D plant modelling at different scales. Graph Models 71:1-21. doi:10.1016/j.gmod.2008.10.001

Rasse DP, Longdoz B, Ceulemans R (2001) TRAP: a modelling approach to below-ground carbon allocation in temperate forests. Plant Soil 229:281-293. doi:10.1023/ A: 1004832119820

Regent Instruments Inc. (2004) WinDENDRO: tree-ring, stem, wood density analysis and measurement, Quebec City, Canada

Reubens B, Poesen J, Geudens G, Muys B (2007) The role of fine and coarse roots in shallow slope stability and soil erosion 
control with a focus on root system architecture: a review. Trees 21:385-402. doi:10.1007/s00468-007-0132-4

Santini S, Wagner B (2010) RootLAB: a matlab framework for the modeling of tree roots. Technical Report No. 696, Department of Computer Science, ETH Zurich, Zurich, Switzerland

Soethe N, Lehmann J, Engels C (2007) Root tapering between branching points should be included in fractal root system analysis. Ecol Model 207:363-366. doi:10.1016/j. ecolmodel.2007.05.007

Tobin B, Čermák J, Chiatante D, Danjon F, Di Iorio A, Dupuy L, Eshel A, Jourdan C, Kalliokoski LR, Nadezhdina N, Nicoll B, Pagès L, Silva J, Spanos I (2007) Towards developmental modelling of tree root systems. Plant Biosyst 141:481-501. doi:10.1080/11263500701626283

Van Noordwijk M, Spek LY, Dewilligen P (1994) Proximal root diameter as predictor of total root size for fractal branching models.1.Theory. Plant Soil 164:107-117. doi:10.1007/ BF00010116
Vercambre G, Pages L, Doussan C, Habib R (2003) Architectural analysis and synthesis of the plum tree root system in an orchard using a quantitative modelling approach. Plant Soil 251:1-11. doi:10.1023/A:1022961 513239

Wagner B, Gärtner H, Ingensand H, Santini S (2010) Incorporating $2 \mathrm{D}$ tree-ring data in $3 \mathrm{D}$ laser scans of coarse-root systems. Plant Soil 334:175-187. doi:10.1007/ s11104-010-0370-x

Wagner B, Santini S, Gärtner H, Ingensand H (2011) Crosssectional interpolation of annual rings within a $3 \mathrm{D}$ root model. Dendrochronologia. doi:10.1016/j.dendro.2010.12.003

Zianis D, Muukkonen P, Mäkipää R (2005) Biomass and stem volume equations for tree species in Europe. Silva Fennica-Monographs no. 4, 63 pp

Zu Castell W, Schrödl S, Seifert T (2005) Volume interpolation of CT images from tree trunks. Plant Biol 7:737-744. doi:10.1055/s-2005-872817 